\title{
A Study on Constructing Long-term Care Insurance System in China
}

\author{
Junzheng You ${ }^{1}$ \\ ${ }^{1}$ School of Management, Shanghai University of Engineering Science, Shanghai, China \\ Correspondence: Junzheng You, School of Management, Shanghai University of Engineering Science, Shanghai \\ 201620, China. Tel: 86-158-0067-0512. E-mail: yjz2018@163.com
}

Received: November 1, 2013 Accepted: November 14, 2013 Online Published: November 25, 2013

doi:10.5430/sass.v1n1p27 URL: http://dx.doi.org/10.5430/sass.v1n1p27

\begin{abstract}
The aging population in China has brought a salient problem, i.e., geriatric care. In this paper, the author summarizes the major measures taken by different countries in the world to solve this prominent problem. Then, the paper compares the long-term care insurance patterns in America and Japan. The author draws experience from these two varied patterns and puts forward the long-term care insurance pattern which is suitable for the national conditions in China.
\end{abstract}

Keywords: population aging, geriatric care, long-term care insurance

\section{Introduction}

The aging population is the common population development trend in every nation in the world. The improvement of modern living quality and the progress of medical technology contribute to extend the average lifespan of human beings. However, the morbidity rate of age-related diseases is increasing, which causes that more and more elderly people are in need of long-term care service. Besides, inflation and the medical fees keep surging, so does the care cost. Therefore, long-term care risk is becoming a social problem which rouses people's great concern. As a result, long-term care insurance comes into being.

It appears more urgent and necessary to establish and keep improving the age-related care insurance system so as to relieve the new social pressure caused by economic and social development and the aging society. In this paper, the author makes a tentative exploration into the long-term care insurance system consistent with the Chinese national conditions.

\section{Prominent Geriatric Care problem Brought by the Aging Population in China}

\subsection{Deterioration of the Aging Process in China}

At present, China is not merely faced with a huge number of aging population. Moreover, the aging is at a fast speed. In particular, the growth rate of the senior elderly over 80 years old is faster than those of the elderly. It is estimated that the proportion of the senior elderly over 80 years old will increase from the current $10 \%$ to $20 \%$ in 2050 . In addition, compared with other groups, the elderly group the most vulnerable group with high morbidity rate of all kinds of diseases. The aging and senility are accompanied with an obvious growth of care needs. Compared with other countries in the world, the aging problem in China is characterized with a large aging population and large amplification, thus suffering from heavier pressure imposed by the aging problem.

\subsection{Change of the Family Structure in China}

With the implementation of the population growth control policy, the population structure in China has taken great places. We can clearly find that there is a trend of miniaturization of the family structure, which has imposed huge social pressure and family pressure on the youth. When their parents are in poorer health, they cannot accompany their parent all the time.

In the urban areas, due to the change of child-bearing concepts, most families have followed the one-child pattern in the past 20 years. At present or later, the " 421 " family composed of four elderly, one couple and one child is and will be a common family structure. If the couple who are both the single child in their families only have one kid, then this third generation will encounter the situation where they have to take care of 12 elderly at most. Most elderly will be under the crisis of weak family care. 


\subsection{Shortage of Care Fund in China}

At current, the care industry in China is faced with salient and severe shortage of care funds. The geriatric care requires for a large amount of investment. In medical care, according to the living dependence degree, care can be classified into complete dependence on care, intense dependence on care and partial dependence on care. The lowest annual care fees of the nursing personnel looking after those partially depend on care is more than 5,000 Yuan. If we calculate with this standard, only the care fees on the 30 million elderly people who cannot take care of their daily life in China reach more than 150 billion Yuan. Besides, it is not realistic for the government to undertake all the care fund. If the family is in charge of all that fees, it is undoubtedly a heavy burden for a considerable number of families.

As a result, we should reflect and re-construct the geriatric care system and mechanism in China. We should draw experience from the developed countries and then look for the appropriate solutions to this problem according to the national conditions in China.

\section{Major international Care System and Long-term Care Insurance Patterns}

\subsection{Major International Geriatric Care Patterns}

At present, there are mainly four types of geriatric care patterns internationally: first, the long-term care insurance system for the elderly. Germany, Japan, America and so on choose to construct the social or commercial insurance system. Second, the custody service pattern. The federal and local government in Australia and other nations undertake part of the custody care fees in accordance with a certain percentage. Third, the pattern of paying the custody fees. France and other nations provide annual care subsides for the elderly who cannot take care of their daily lives and need others' care. Moreover, those elderly people's annual income is lower than the lowest income standard. Four, the pattern of paying family allowance. Switerland, Finland and other north European nations offer care fees monthly or yearly to the elderly who cannot take care of their daily life in accordance with the care needs.

Comparing the patterns providing care service, we can find that the latter three patterns are in the charge of the government or implemented by means of governmental subside. These patterns require for solid financial strength. There are few nations adopting these patterns. In addition, they are not consistent with the national condition in China. In terms of the first one, i.e., constructing the long-term care insurance pattern, a majority of nations choose this one. Besides, China possesses certain foundation to implement this model. We can draw experience and reference from this pattern and take it into consideration.

\subsection{Major Long-term Care Insurance Patterns}

There are two different patterns in the long-term care insurance according to the different main bodies undertaking the funding responsibilities: the first one is the commercial insurance pattern, which requires that the individual and family should undertake the major funding responsibilities of long-term care insurance. When the government cannot undertake the funding responsibility, the individual and family should supplement and take the funding responsibility. America is typical of the countries which adopt the pattern. The other type is compulsory insurance pattern, which is implemented forcibly by laws. The country, enterprise and individual share the responsibility of the insurance funding responsibility; or the country and individual share the responsibility. This pattern is outstanding in Japan. Next, the author will make some brief analysis:

\subsubsection{Compulsory Care Insurance Pattern--Japanese Pattern}

Japan's care insurance system. The most direct reason of Japan's geriatric care insurance system is the aging population. In 1995, the Japanese government put forward the bill of "About establishing care insurance system". On April 1, 2000, it was launched into implementation. As one of the governmental welfare policies, the long-term care insurance in Japan, endowment insurance, medical care insurance and unemployment insurance comprise social insurance system, which belongs to social insurance scale. In addition, Japan establishes care insurance laws to enforce the regulation.

The characteristics of Japan's care insurance system: (1) Japan's geriatric care system is formed through integrating the geriatric welfare system and the geriatric insurance medical care system. This is executed by all levels of social welfare departments. It is a kind of compulsory social insurance system taken part in by the civilians over 40 years old. (2) The classified insurance fee charging demonstrates the characteristics that the government undertakes the fees on a hierarchical basis and that the insured people who benefit the most pay the most fees. The national financial payment accounts for $50 \%$ of the care insurance feels; and the insured undertake the other half. The insured over 65 years old take up for $33 \%$ of the insurance fees; and the insured from 40 to 65 years old account for 17\%.(3) It 
restricts the scale of the insured people. The insured are classified into two types. The first type of the insured are those elderly over 65 years old who is afflicted with dementia or cannot deal their lives and stay in bed. The second type of the insured people ranges from 40 to 65 years old. These people are restricted as those who are afflicted with diseases affecting the ability of dealing with daily life due to aging and who are in need of special care services.

\subsubsection{Commercial Care Insurance Pattern--American Pattern}

The geriatric care insurance in America adopts the commercial form. The commercial insurance company is in charge of developing the geriatric care insurance. The insured takes part in this type of insurance pattern voluntarily through purchasing the care insurance contract. The warranty of the commercial care insurance can be signed and issued separately. It can also be signed and issued in the form of the endorsement of the whole-life insurance warranty. The medical care assistance program established by the state in the US provides certain subsides for the insurance fees of geriatric care insurance of the poor. The main contents are: (1) the insurance responsibilities: the long-term care insurance undertakes the care fees generated by the personal care service for the insured at any place (except emergency treatment). These care services include: curative care services, such as diagnosis, prevention, rehabilitation and other non-curative family care, adult daily care and so on. (2) Insurance-acceptance methods: long-term care warranty can also be signed and issued independently, which can also be signed and issued in the form of the endorsement of the whole-life insurance warranty. Usually, the risk selection is carried out from age, medical care status and disease history and other aspects of the insured. (3) Insurance fee charging. The long-term care insurance generally is charged based on the average annual fee ratio according to the age of the insured when he or she applies for insurance. The detailed insurance amount depends on the payment time, waiting period and the scale of the insurance responsibility and so on besides the age of the insured.

\section{Implications of the Two Care Insurance Patterns on China}

The long-term care insurance patterns in America and Japan are established based on their own specific national conditions, which have both advantages and disadvantages. It is of great significance for China to draw reference in constructing the long-term care insurance through analyzing and comparing the two patterns.

\subsection{Analysis of Adopting America's Commercial Long-term Care Insurance Pattern}

In China, if we completely adopt the fund-raising method of American commercial long-term care insurance pattern, it not only requires for high per capital income, but also requires for developed commercial health insurance market. However, the commercial health insurance market in our country is not mature. Moreover, the commercial medical care insurance does not enjoy sound development in our nation. Take the situation in 2006 for example. In 2006, the participants of commercial health insurance reached nearly 7.8888 million (only accounted for $6 \%$ of the whole population). However, in 2005, the American commercial health insurance covered $84 \%$ of the population. In 2006 , the income of our national commercial health insurance reached 37.690 billion Yuan. There was an increase of $21.65 \%$, but it only took up for $9.1 \%$ of the life insurance revenue. From this, we can see that commercial health insurance plays a small role in the medical care industry in our country. The commercial health insurance system is relatively underdeveloped, which indicates that if we launch commercial long-term insurance, we may face a variety of problems, such as those encountered by commercial health insurance, including unsound risk control mechanism, high compensation ratio, high moral risks, high insurance premiums, small differences among different insurance types, shortage of flexibility, failure in meeting diverse needs and so on. At the same time, we may also come across inadequate effective insurance supply, surging care fees and so on. On the other hand, because the per capita disposable income in our country is low, if we take the measure of purchasing commercial long-term care insurance individually, it is definite that a lot of people cannot afford the insurance, which thus cannot solve the problem faced by the whole social elderly in terms of their care service needs. As a result, there will be no fairness.

\subsection{Analysis of Adopting Japan's Compulsory Long-term Care Insurance Pattern}

Adopt completely Japan's compulsory long-term care insurance system. At present, as a developing country, if China adopts Japan's compulsory long-term care insurance pattern which requires the government and the individual to undertake half of the fees respectively, we will encounter bigger problems.

First, China is still a developing country now with its economy backward. In particular, our country is facing the big absolute number of the elderly, the fast development and aging-before-getting-rich of aging and the elderly care percentages. It is unlikely for the country and the local financial institutions to take a large amount of budget to pay the insurance.

Second, from a personal perspective, because the economy of our nation is relatively backward and that per capita GDP is low, the individuals may not pay more tax to support the long-term care insurance for the elderly. On the 
other hand, the low personal disposable income decides that the other half of the insurance fee paid by the individuals cannot be realized, either. In particular, for the elderly in the rural areas, their income is not high, which is not adequate to pay the long-term care insurance. Some elderly are even conservative and poorer. When they are sick, they cannot afford the treatment of the medical care institutions, let alone accepting the long-term care.

As a result, when the economy is not developed and that the per capita income is low in our country now, we cannot adopt the compulsory long-term care insurance payment pattern.

\section{Establish Long-term Care Insurance Pattern Suitable for China's National Conditions}

\subsection{Commercial Long-term Care Insurance Pattern}

Under the current economic situation in China, it is the best choice to develop commercial long-term care insurance. To be specific, we can launch the commercial long-term care insurance among the middle class or higher in the towns or cities with developed economy. However, we must notice that adopting commercial long-term care insurance may cause that a lot of family with a low income cannot receive insurance. As a result, after the commercial long-term care insurance is launched for a period of time, we should transit gradually to the combination of commercial long-term care insurance and basic social care insurance. The commercial long-term care insurance can serve as a supplement of the basic social long-term car insurance.

\subsection{Combination of Commercial Long-term Care Insurance and Basic Social Long-term Care Insurance}

Through establishing commercial long-term care insurance, we can enable the whole society to have a common understanding of the insurance type. Besides, after improving the awareness of the government, residents, enterprise employers, employees and so on, we can refer to the measures take by the ordinary commercial medical care insurance and basic medical care insurance to publicize this insurance in the whole society. We should cover all the companies and the employees with the basic long-term care insurance form to meet the basic needs of geriatric care. The reason why the pattern is feasible is because it can guarantee the long-term care insurance needs of a majority of people and meet the demands of the rich on high-level long-term care insurance through purchasing commercial long-term care insurance.

\subsection{Civil Long-term Care Insurance Pattern Forcibly Implemented by the Government}

After the two steps above, long-term care insurance should take deep roots among the masses and spread in a large scale. When the economic development in our country keeps up with the developed countries, we can enter the third phase, i.e., the civil long-term care insurance pattern forcibly implemented by the government, which is similar to the pattern chosen in Japan. The government undertakes about half of the fund, the provincial; municipal and local government is responsible for a proportion; and the civilian pays a small proportion of funds (the employer and the employee can share the responsibility jointly) in financing. Although the pattern enables to civilians to enjoy the right of long-term care fairly, the prerequisite must accord with developed economic level, improved civilians' quality, developed care institutions, perfect legal systems and sound communication facilities and network facilities. As a result, the current pattern is unfeasible. However, with the development of our economy, improvement of civilians' quality and perfection of each system, the pattern may become a reality in the future. Moreover, our society will become one harmonious one where the elderly are taken good care of with high welfare level.

\section{Conclusion}

Through the comparison and analysis of the experience of the successful long-term care insurance systems in America and Japan, I think the long-term care insurance pattern suitable to our national conditions should be in three steps: Step 1, we should adopt commercial long-term care insurance pattern; Step 2, we should combine the basic social long-term care insurance jointly participated by the country, enterprise and the individuals and the commercial long-term care insurance. The latter one should be the complementary insurance pattern. Step 3, we should implement the civil long-term care insurance pattern forcibly implemented by the government.

\section{References}

Jiang, Hong. (2006). Discussion on Developing the Long-term Care Insurance in China. Insurance Studies, 10, $38-40$.

Zhang, Ming. (2009). Research on Demand Influencing Factors of Elderly Care Insurance System. Dalian University of Technology.

Tong, Limin. (2008). Implications of Japan's Care Insurance System on Shanghai. East China Normal University.

Ding, Chun, \& Qu, Qianchao. (2008). Overview on German Care Insurance System: Historic Cause, Operational 
Characteristics and Reformation Plans. Deutschland - Studien, 3, 44.

Yao, Haiming. (2006). Overseas Geriatric Care Insurance System and Its Implications on China. Modern Economic Research, 6, 43-44.

Wang, Huali. (2008). Market Investigation and Development Measures on Long-term Care Insurance in Shanxi. On Economic Problems, 7, 128.

Chen, Jing. (2009). Revision of Japan's Care Insurance System and Old-age Care Participation of Non-profit Organizations. Population Journal, 2, 57.

Yu, Shan. (2008). Inspiration and Implications of Japan's Care Insurance System on China. Rural Economy and Science-Technology, 12, 7.

Jing, Tao. (2007). Exploration in Developing Old-age Long-term Care Insurance in China. Chinese Journal of Gerontology, 3, 298. 